FUELLS

11. 'DEVELOPMENT OF URANIUM MONONITRIDE FUELS

P. Patriarca J. L. Scott

Uranium mononitride (UN) is potentially attractive as fuel for space nuclear reactors because of its excellent stability at high temperatures, high thermal conductivity, and good irradiation stability up to $1000^{\circ} \mathrm{C}$. The purpose of this program is to determine the basic mechanisms of fuel swelling and gas release at temperatures above $1000^{\circ} \mathrm{C}$. Results will be used to develop a model for predicting the performance of UN as a function of temperature, burnup, and cladding restraint.

\title{
Irradiation Testing
}

\section{T. N. Washburn}

The basic objective of the ORNL program ${ }^{1}$ for irradiation testing of UN is to investigate the capability of this fuel material for performance at high temperatures and low heat ratings. We are interested in fuel temperatures of 1000 to $1500^{\circ} \mathrm{C}$, temperatures at the outside surface of the cladding of 900 to $1400^{\circ} \mathrm{C}$, and linear heat ratings from 5 to $10 \mathrm{~kW} / \mathrm{ft}$. Fuel properties of most interest are swelling rate, release of fission gas, and compatibility with the cladding materials. The irradiation tests are conducted in the poolside facilities of the ORR. These facilities allow adjustment of the position of the test capsule relative to the reactor face and thereby make it possible to maintain a constant temperature at a selected reference point on the test specimen as the reactor flux profile changes or as the fissile content of the test fuel is diminished.

Postirradiation Examination of Capsule UN-3 (T. N. Washburn, E. L. Long, Jr., D. R. (uneo')

We previously reported the nondestructive portion of the examination of the three fuel pins of capsule UN-3 (ref. 3) and the metallographic 


\section{DISCLAIMER}

This report was prepared as an account of work sponsored by an agency of the United States Government. Neither the United States Government nor any agency Thereof, nor any of their employees, makes any warranty, express or implied, or assumes any legal liability or responsibility for the accuracy, completeness, or usefulness of any information, apparatus, product, or process disclosed, or represents that its use would not infringe privately owned rights. Reference herein to any specific commercial product, process, or service by trade name, trademark, manufacturer, or otherwise does not necessarily constitute or imply its endorsement, recommendation, or favoring by the United States Government or any agency thereof. The views and opinions of authors expressed herein do not necessarily state or reflect those of the United States Government or any agency thereof. 


\section{DISCLAIMER}

Portions of this document may be illegible in electronic image products. Images are produced from the best available original document. 
examination of the middle fuel pin ( $\mathrm{T}-111$ cladding) that had failed during the irradiation test, ${ }^{4}$ the bottom fuel pin (T-IIl cladding) 5 and the top fuel pin ( $W-25$ wt $\%$ Re cladding). 6

The fuel pins and operating conditions of capsule UN-3 are described in Fig. 11.1. The scheduled 10,000 hr irradiation experiment was terminated after $5800 \mathrm{hr}$ when detection of fission gases in the capsule indicated that one of the fuel pins had failed. We do not know what led to failure of the T-11l cladding of the middle fuel pin and incipient failure of the T-11l cladding of the bottom fuel pin. Our summary conclusion is that this batch of T-lll was not a satisfactory cladding material under the conditions of this experiment $\left(1400^{\circ} \mathrm{C}\right.$ at outside surface of cladding and 1500 to $1550^{\circ} \mathrm{C}$ at fuel center). The W-25 wt \% Re cladding showed no evidence of unsatisfactory performance at $1300^{\circ} \mathrm{C}$ at the outside surface of the cladding and $1400^{\circ} \mathrm{C}$ at the fuel center.

All three of the fuel pins in this test had acceptable diametral swelling of less than $0.5 \% \triangle \mathrm{D} / \mathrm{D}$ (where $\mathrm{D}$ is diameter). The middle and

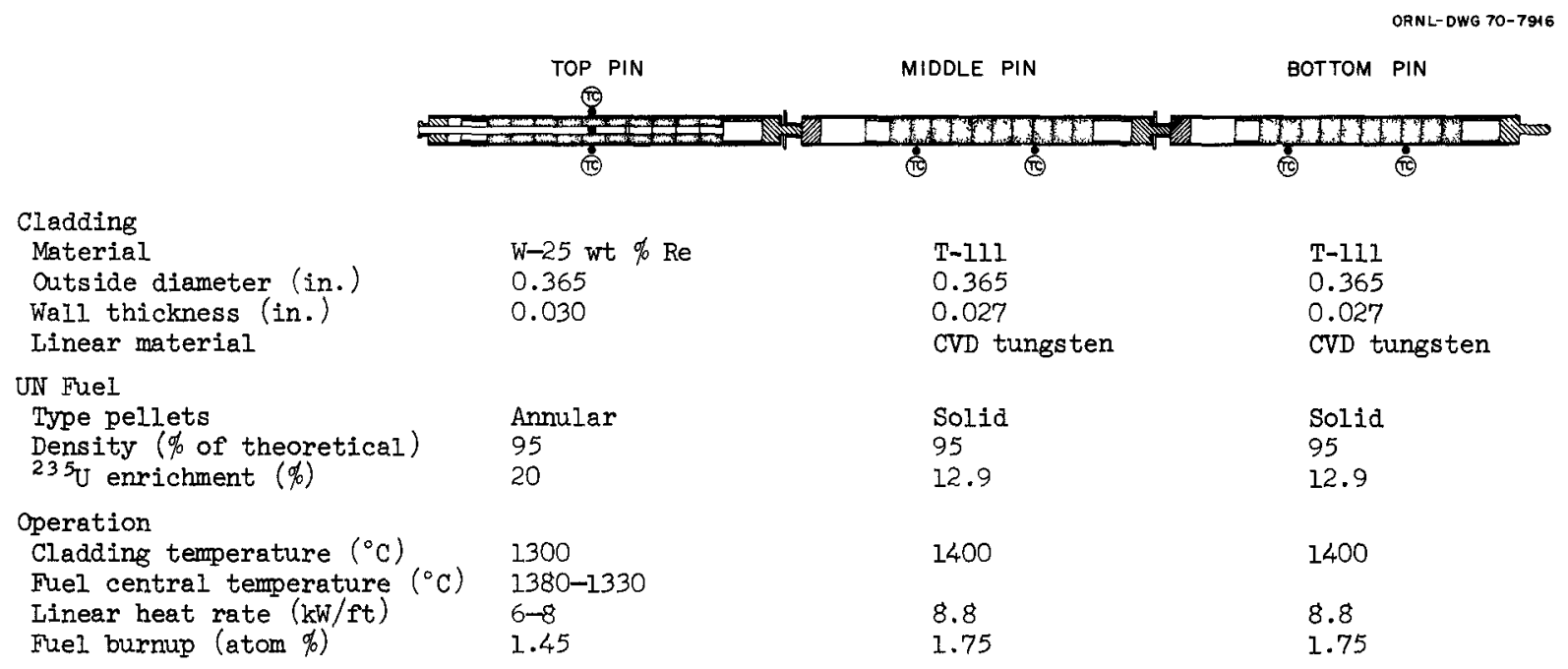

Fig. 11.1. Fuel Pins of Capsule UN-3. 
bottom pins, which were clad with T-111, had maximum swelling of 0.5 and $0.4 \%$, respectively; the top pin, which was clad with $W-25$ wt $\%$ Re, had decreased $0.7 \%$ in diameter. The T-1Il pins also had local regions of diametral decrease caused by the creep collapse of the claddings at $350 \mathrm{psi}$ overpressure applied to prevent the NaK heat-transfer medium from boiling. The creep was uniform; the claddings were not wrinkled or significantly oval.

Although the diametral changes of the fuel pins were low, the fuel volume increased $3.3,6.0$, and $4.5 \%$ for the top, midale, and bottom pins, respectively. These volume increases were accommodated by the initial gap between the fuel and cladding and by an increase in the fuel length of $2.3 \%$ in each pin.

The release of fission gases generated from the fuel bodies was low (0.1\% for the top pin and $7.1 \%$ for the bottom pin), but the method by which the fission gas was retained led to swelling. The typical appearance of irradiated UN fuel from the bottom pin is shown in Fig. 11.2.

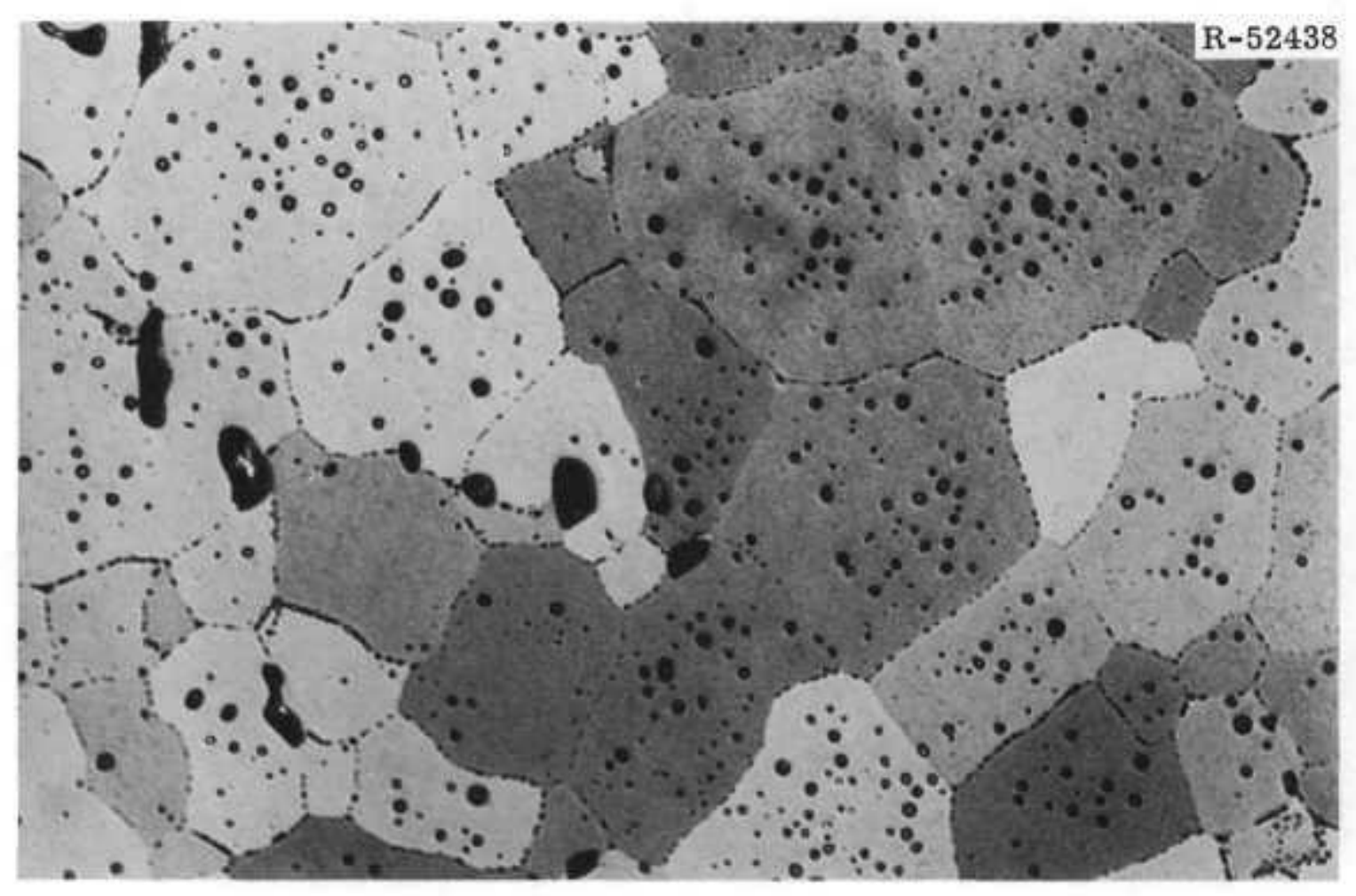

Fig. 11.2. Metallographic Appearance of Irradiated UN Fuel from Bottom Pin of Capsule UN-3. 500x. 
The large pores within the grains were principally Pabricated porosity, but the porosity at the grain boundaries was caused by accumulation of fission gases. The porosity at the grain boundaries is shown more clearly in Fig. 11.3 by transmission electron microscopy of replicas of fractured UN surfaces. The intergranular fracture shows massive coalescence of bubbles of fission gas at grain boundaries. The transgranular
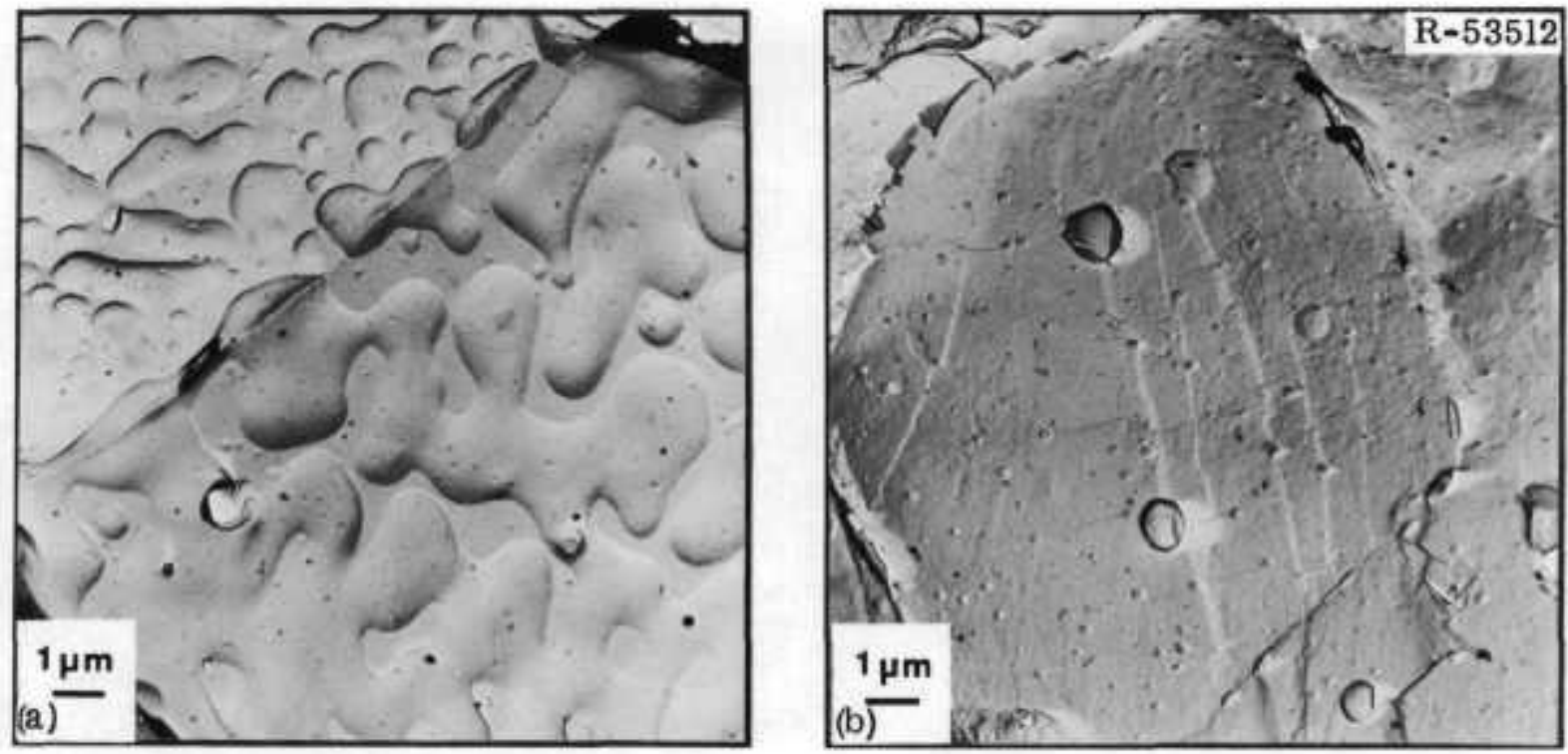

Fig. 11.3. Fractographic Surfaces from the Central Region of a UN Fuel Pellet from Bottom Fuel Pin, Capsule UN-3. (a) Intergranular and (b) transgramular. Carbon replica shadowed with chromium.

fracture shows small bubbles of fission gas in the grain as well as larger pores that we believe to be fabricated porosity. A similar comparison of the appearance of the transgramular and intergranular fractures by scanning electron microscopy of replicas is shown in Fig. 11.4. The coalescence of the fission gases at the grain boundaries forces the grains apart and produces substantial swelling of the fuel, although the fission gases are not released in large quantity from the fuel body. It was established that elimination of grain boundaries by use of singlecrystal UN effectively reduces volume increases during irradiation." Other investigators showed similar results by use of large-grained or porous UN fuel. 8 

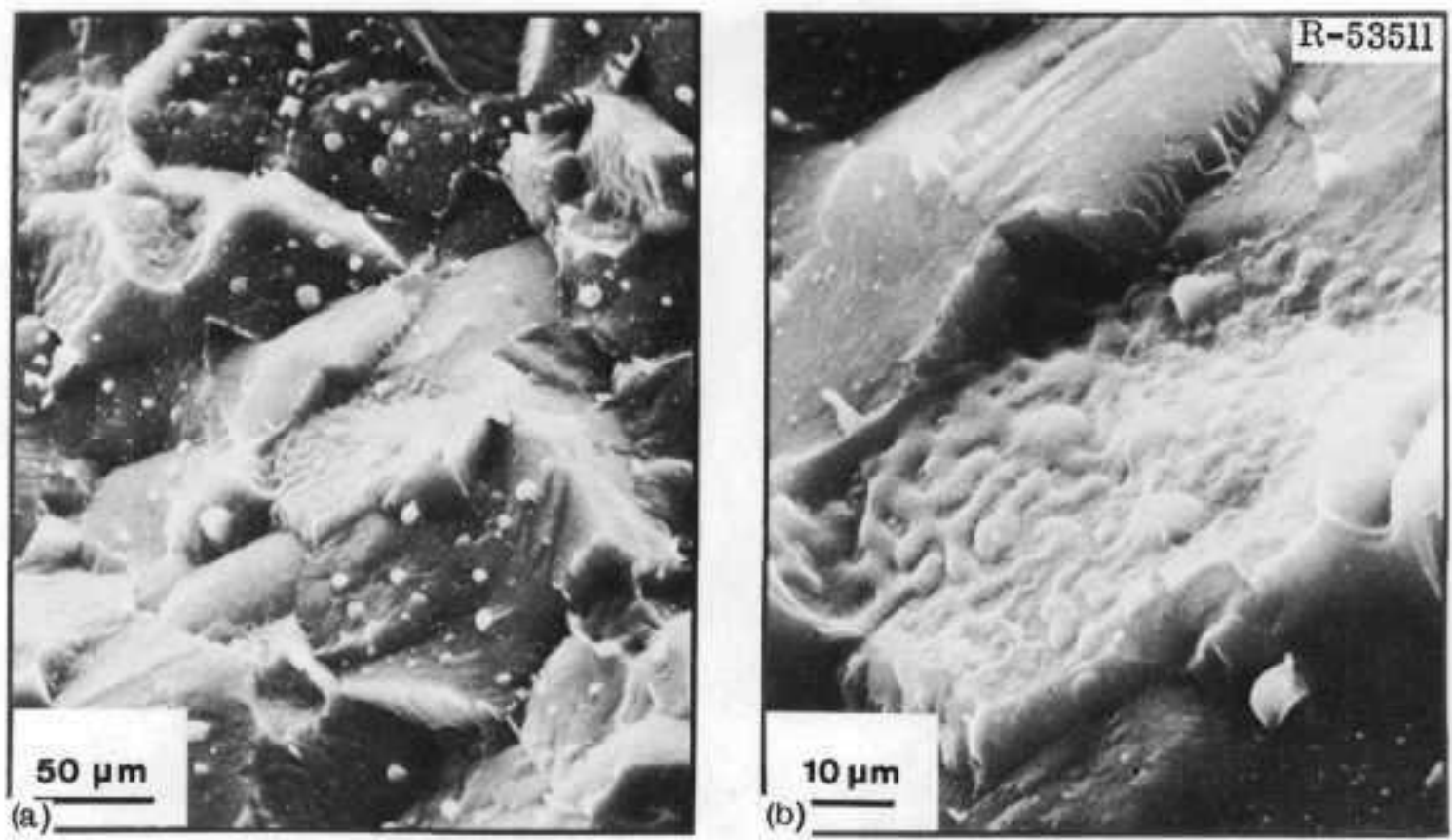

Fig. 11.4. Scanning Electron Fractographs of Central Region of a UN Fuel Pellet from Bottom PIn of Capsule UN-3. (a) Transgranular and intergramular and (b) intragranular. Plastic replica shadowed with gold.

Intergramular Fractures in T-111 in Capsule UN-3 (A. Jostsons,? E. L. Long, Jr., D. R. Cuneo')

Metallographic sections through the cracked regions of the cladding of the middle fuel pin in capsule UN-3 showed that it failed intergranularly. More detailed metallurgical investigations of failed and unfailed T-111 cladding revealed general cavitation at grain boundaries, which may limit the usefulness of T-111 as a cladding material at high temperatures.

A representative metallographic cross section of the chemically vapor deposited (CVD) W IIner and T-111 cladding removed from failure regions is shown in Fig. 11.5. In addition to the band of porosity at the interface between $W$ and $T-111$, porosity and cracks were present at grain boundaries in both the W Iiner and the inner parts of the T-11I. cladding. Porosity at grain boundaries in T-111 apparently precedes the formation of intergramular cracks. The UN fuel extruded into some of the cracks shown in the W liner in Fig. 11.5, thereby demonstrating that these cracks existed at temperature and that the fuel pin experienced considerable stress. The cracked W liner is apparently ineffective as 

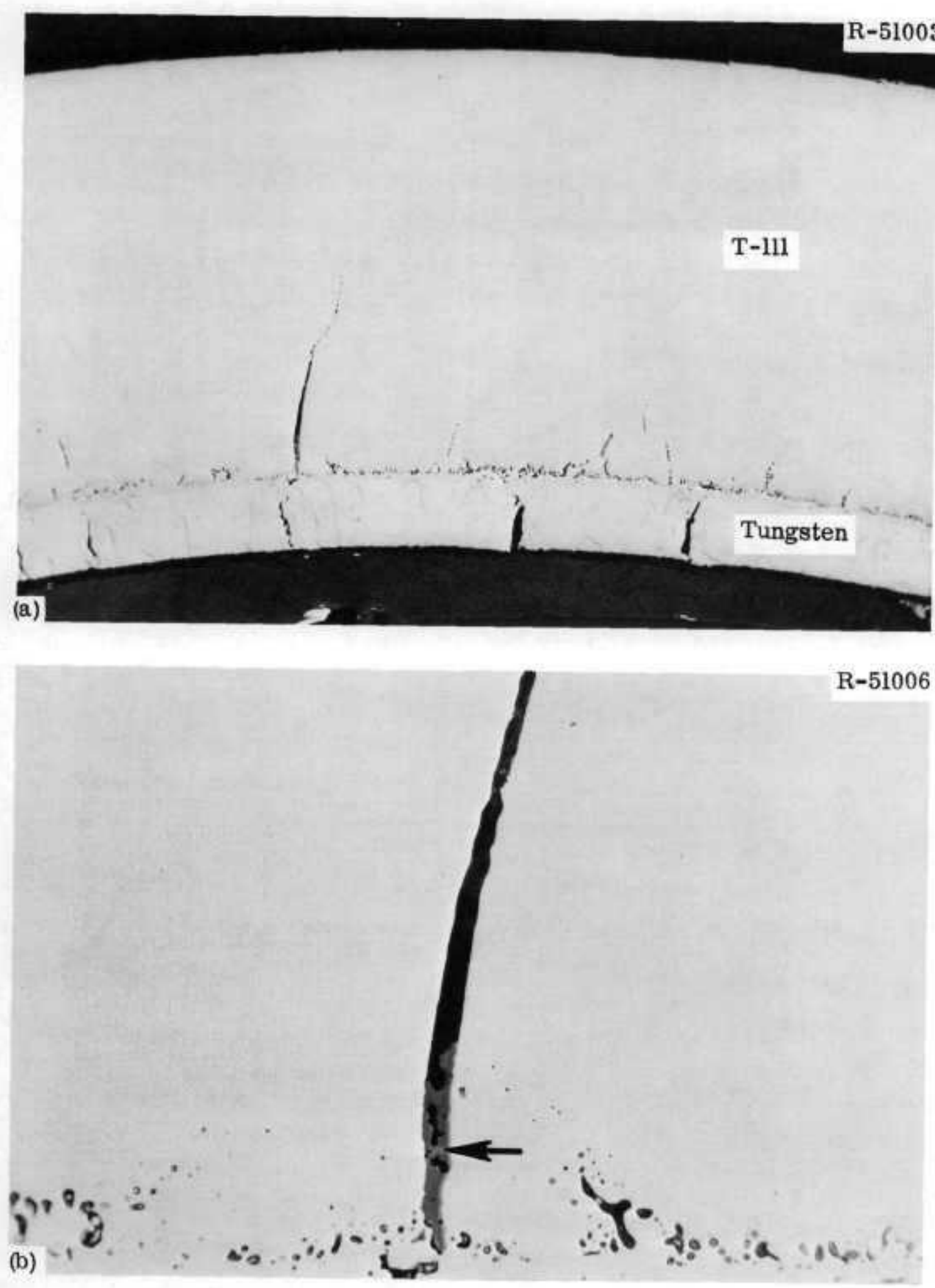

Fig. 11.5. Appearance of a Transverse Section Through Chemically Vapor Deposited Tungsten Liner and T-111 Cladding. (a) 100x, and (b) higher magnification $(500 x)$ view of gray phase (arrow) occasionally found in the intergramular cracks in the T-1.11 and tungsten. As polished. 
a barrier to protect the T-11l from gaseous $\mathrm{N}_{2}$ if the temperature is high enough for a significant $\mathbb{N}_{2}$ overpressure.

Since the irradiated cladding from both pins was brittle at room temperature, we readily obtained replicas from fresh fractures. Scanning electron micrographs of a replica taken from cladiling fractured longitudinally near the failed region are shown in Fig. 11.6. The large variation in grain size between regions about $1 \mathrm{~cm}$ apart provides additional support for our earlier hypothesis that localized hot spots developed in the cladding during irradiation. Large cavities at grain boundaries in the $T-111$ cladding near the interface with the $W$ lines are apparent in Fig. $11.6(a)$. Higher magnification of the finer grained region, shown in Fig. $11.6(\mathrm{~b})$ also revealed cavities at grain boundaries throughout the thickness of the cladding; the size of the cavities decreased from the inside to the outside surfaces of the cladding. Numerous cavities were present at the grain boundaries in the W liner, which also fractured intergranularly (Fig. 11.7).

Farrell et al. ${ }^{10}$ and Stiegler et al. ${ }^{11}$ extensively studied the nature of cavities at grain boundaries in CVD $\mathrm{W}$. They concluded

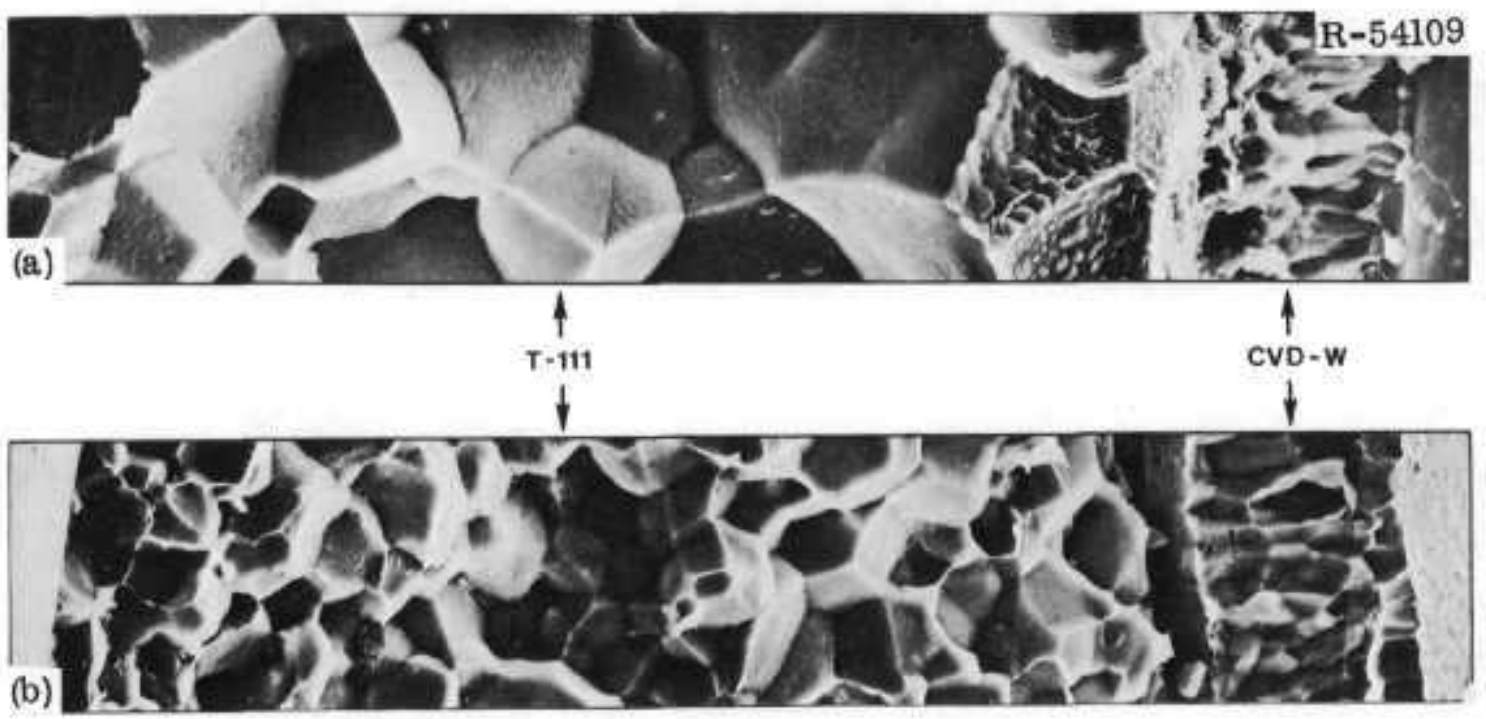

Fig. 11.6. Scanning Electron Micrographs of Two Fracture Surfaces about $1 \mathrm{~cm}$ Apart. (a) Region of large grains near failed region of cladding, and (b) region of smaller grains. Plastic replica shadowed with gold. About $200 \times$. 


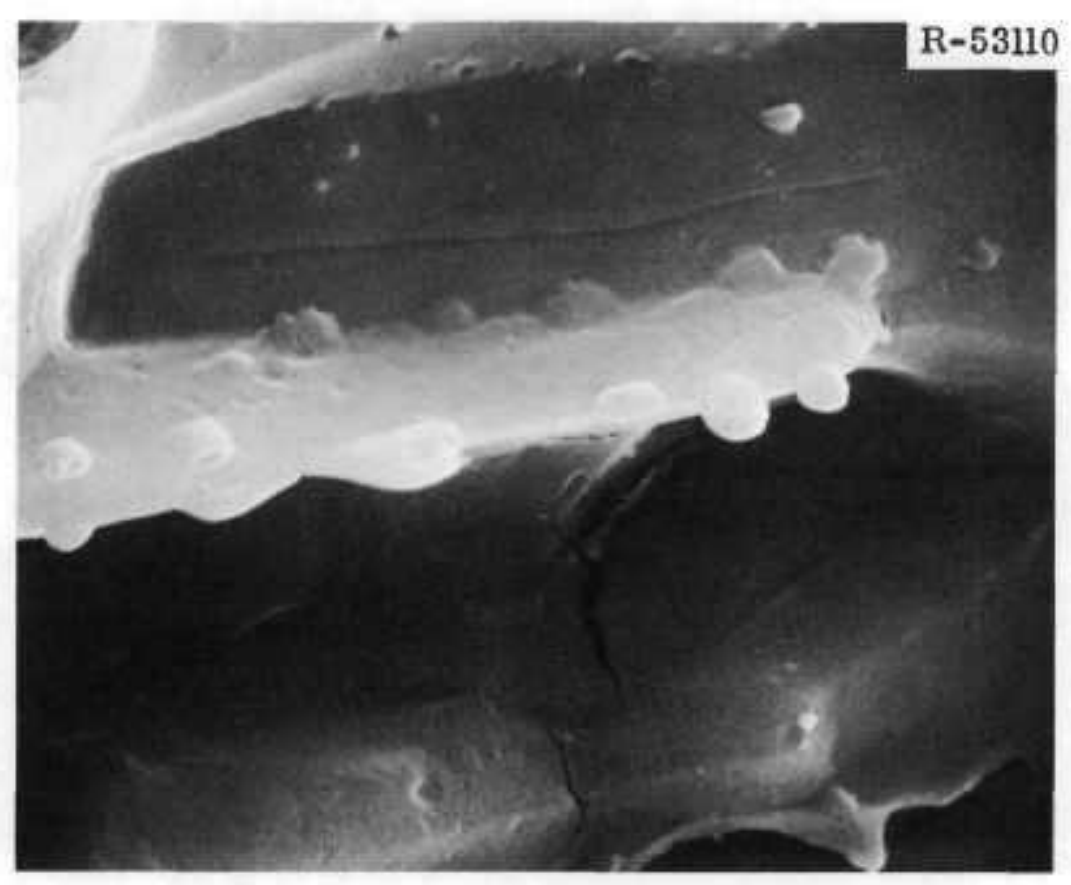

Fig. 11.7. Cavities at Grain Boundaries in Chemically Vapor Deposited Tungsten Liner as Revealed by Scanning Electron Microscopy. Plastic replica of a fracture surface shadowed with gold. $3000 \times$.

that the cavities were small bubbles of a presently unidentified gas. The size of these bubbles was dependent on both temperature and stress. Bubbles were observed at grain boundaries by transmission electron microscopy after annealing at $1400^{\circ} \mathrm{C}$ or higher. Thus, our present observation of cavities at grain boundaries in the CVD W liner is not surprising, particularly in the presence of stress and supersaturation of vacancies induced by irradiation.

The explanation of cavities at grain boundaries is not as simple for T-111 as it is for CVD $W$. Creep-mpture specimens of unirradiated T-111 fractured at $1400^{\circ} \mathrm{C}$ were ductile (fracture strain $>25 \%$ ) and did not fracture intergramularly even below room temperature. ${ }^{12}$ We do not yet know what mechanism is responsible for promoting the formation of cavities at grain boundaries in T-111. We are contimuing our investigation of the possible effect of the Hf concentrations at the cavities and are trying to determine the chemical form of the Hf. 
Fabrication of Irradiation Capsules (E. J. Manthos)

We are fabricating three capsules for irradiation tests in the ORR. Two of these capsules (UN-4 and UN-5) will each contain three fuel pins of UN pellets in T-1ll ( $\mathrm{Ta}-8 \% \mathrm{~W}-2 \% \mathrm{Hf}$ ) cladding with a $\mathrm{W}$ liner to separate the fuel and cladding to minimize incompatibility of these two materials. The six fuel pins were fabricated, the capsules are being assembled, and the experiments are scheduled to be inserted into the reactor in February 1971. The third capsule (UN-6) will contain three fuel pins with $\mathrm{UO}_{2}$ pellets. Two of the fuel pins will have $\mathrm{Nb}-1 \% \mathrm{Zr}$ cladding, and the third will have T-IIl cladding. Incompatibility of fuel and cladding will be minimized with a $W$ liner. The fuel pin loadings are shown in Table 11.1

Table 11.1. Fuel Pin Loadings for Capsule UN-6

\begin{tabular}{llc}
\hline $\begin{array}{l}\text { Fuel } \\
\text { Pin }\end{array}$ & Cladding & $\begin{array}{c}23 \mathrm{U} \text { Enrichment } \\
\text { (at. \%) }\end{array}$ \\
\hline Top & $\mathrm{Nb}-1 \% \mathrm{Zr}$ & 10 \\
Middle & $\mathrm{T}-111$ & 10 \\
Bottom & $\mathrm{Nb}-1 \% \mathrm{Zr}$ & 8 \\
\hline
\end{tabular}

The fuel burnup in $8000 \mathrm{hr}$ will be $2 \%$, the cladding temperature will be at least $1000^{\circ} \mathrm{C}$, and the temperature at the fuel center will not exceed $1600^{\circ} \mathrm{C}$.

Fabrication of the pellets was begun and should be completed in Jamuary 1971. We procured and are inspecting $\mathrm{Nb}-1 \% \mathrm{Zr}$ bar stock for end fittings. Tubing for the fuel cladding is being fabricated from $\mathrm{Nb}-1 \% \mathrm{Zr}$ rod.

We have T-11l cladding and end fittings and $W$ liners on hand. Components for a $\mathrm{Nb}-1 \% \mathrm{Zr}$ container for $\mathrm{NaK}$ were fabricated; the NaK vessel was rejected, however, and a new one will be fabricated. The bulkhead and cap were found to be satisfactory. Capsule UN- 6 is scheduled to be inserted into the reactor on April 25, 1971. 
Proposed Irradiation Tests of UN in the EBR-II (B. Fleischer, T. N. Washburn, M. K. Preston 13)

We reviewed previous irradiation tests in thermal-flux environments of UN fuel pins clad with refractory metal. Since these tests were generally successful, further testing is warranted to establish the suitability of proposed designs for compact fast-flux reactors. Accordingly, we are developing a program of irradiation tests to evaluate promising combinations of fuel and cladding for a fast flux.

We propose to perform our irradiations in row 6 or 7 in the EBR-II. To select the most desirable site, we calculated relative power levels for typical positions in the reactor. The values for these locations of interest are shown in Table 11.2. The relative power levels shown for a $6 \mathrm{~N}-1$ location allow us to achieve heat ratings from 4 to $11.5 \mathrm{~kW} / \mathrm{ft}$ with only two levels of fuel enrichment. By staggering the withdrawal times, we shall also be able to investigate the effect of burnup at the various power levels. The cladding temperature of $1000^{\circ} \mathrm{C}$ during the initial tests will allow the use of $\mathrm{Nb}-1 \% \mathrm{Zr}$ as well as $\mathrm{T}-111$ and $\mathrm{W}-25 \%$ Re as cladding materials. To provide space for accumulation of gas while keeping the pin short, we shall use $95 \%$ dense annular fuel pellets in the initial experiments.

A conceptual design of the proposed test unit was made for an uninstmumented B-7B subassembly that will hold seven test capsules. Each capsule will contain three pins, thus providing 21 test positions. An isometric view of the test unit is presented in Fig. 11.8 together with a list of the materials and dimensions of interest. The fuel pin is thermally coupled to the $\mathrm{Nb}-1 \% \mathrm{Zr}$ primary container with either $\mathrm{Na}$ or $\mathrm{Li}$. By matching the width of the intermediate He gap to the heat ratings, we shall be able to obtain the desired cladding temperature. The outer $\mathrm{Na}$ gap will thermally couple the secondary containment to the outer containment vessel, thus providing a total of 4 containment vessels between the UN fuel and the EBR-II coolant. As applicable, a $W$ barrier material will be used around the UN fuel to prevent physical contact and possible reaction of the UN with either $\mathrm{Nb}-1 \% \mathrm{Zr}$ or T-111. Further definition of the test program and improved conceptual design of the capsule are continuing. 
Table 11.2. Power Levels of Selected Subassembly Locations in the EBR-II

\begin{tabular}{|c|c|c|c|c|c|}
\hline \multicolumn{2}{|c|}{ Subassembly $6 \mathrm{~N}-1$} & \multicolumn{2}{|c|}{ Subassembly $7 \mathrm{~N}-4$} & \multicolumn{2}{|c|}{ Subassemblies $7 \mathrm{~N}-3$ and $7 \mathrm{~N}-5$} \\
\hline $\begin{array}{c}\text { Pin } \\
\text { Location }^{\mathrm{a}}\end{array}$ & $\begin{array}{l}\text { Relative } \\
\text { Power } \\
\text { Level } \\
\end{array}$ & $\begin{array}{l}\text { Pin } \\
\text { Location }^{a}\end{array}$ & $\begin{array}{c}\text { Relative } \\
\text { Power } \\
\text { Level } \\
\end{array}$ & $\underset{\text { Location }^{2}}{\text { Pin }}$ & $\begin{array}{l}\text { Relative } \\
\text { Power } \\
\text { Ievel } \\
\end{array}$ \\
\hline $1 B$ & 1.26 & $1 B$ & 1.30 & $1 B$ & 1.27 \\
\hline $2 \mathrm{~B}$ & 1.26 & $2 \mathrm{~B}$ & 1.20 & $2 \mathrm{~B}$ & 1.20 \\
\hline $1 \mathrm{C}$ & 1.13 & $3 \mathrm{~B}$ & 1.20 & $3 B$ & 1.14 \\
\hline $2 \mathrm{C}$ & 1.13 & IC & 1.17 & $1 \mathrm{C}$ & 1.13 \\
\hline $3 \mathrm{~B}$ & 1.12 & $4 \mathrm{~B}$ & $\begin{array}{l}1.11 \\
1.10\end{array}$ & $2 \mathrm{C}$ & 1.08 \\
\hline $4 \mathrm{~B}$ & 1.12 & $1 \mathrm{~A}$ & 1.08 & $4 \mathrm{~B}$ & 1.08 \\
\hline $5 \mathrm{~B}$ & 1.12 & $2 \mathrm{C}$ & 1.08 & $1 \mathrm{~A}$ & 1.05 \\
\hline $1 \mathrm{~A}$ & 1.05 & $3 \mathrm{C}$ & 1.08 & $3 \mathrm{C}$ & 1.01 \\
\hline $2 \mathrm{~A}$ & 1.05 & $5 \mathrm{~B}$ & 1.01 & $5 \mathrm{~B}$ & 1.01 \\
\hline $3 \mathrm{C}$ & 1.00 & $6 \mathrm{~B}$ & 1.01 & $2 \mathrm{~A}$ & 1.00 \\
\hline $4 \mathrm{C}$ & 1.00 & $2 \mathrm{~A}$ & 1.00 & $4 \mathrm{C}$ & 0.96 \\
\hline $5 \mathrm{C}$ & 1.00 & $3 A$ & 1.00 & $6 B$ & 0.95 \\
\hline $6 \mathrm{~B}$ & 0.96 & $4 C$ & 1.00 & $3 A$ & 0.95 \\
\hline $7 B$ & 0.96 & $4 A$ & 0.92 & $5 \mathrm{C}$ & 0.91 \\
\hline $3 \mathrm{~A}$ & 0.93 & $7 B$ & 0.92 & $4 \mathrm{~A}$ & 0.90 \\
\hline $4 \mathrm{~A}$ & 0.93 & $5 \mathrm{C}$ & 0.90 & $7 B$ & 0.89 \\
\hline $5 \mathrm{~A}$ & 0.93 & $6 \mathrm{C}$ & 0.90 & $6 \mathrm{C}$ & 0.85 \\
\hline $6 \mathrm{C}$ & 0.86 & $5 \mathrm{~A}$ & 0.84 & $5 \mathrm{~A}$ & 0.85 \\
\hline $7 \mathrm{C}$ & 0.86 & $6 \mathrm{~A}$ & 0.84 & $7 \mathrm{C}$ & 0.80 \\
\hline $6 \mathrm{~A}$ & 0.79 & $7 \mathrm{C}$ & 0.82 & $6 \mathrm{~A}$ & 0.79 \\
\hline $7 \mathrm{~A}$ & 0.79 & $7 \mathrm{~A}$ & 0.76 & $7 \mathrm{~A}$ & 0.74 \\
\hline \multicolumn{2}{|c|}{$\begin{array}{c}\text { Center line } \\
\text { reactor }\end{array}$} & \multicolumn{2}{|c|}{$\begin{array}{c}\text { Center line } \\
\text { reactor } \\
\end{array}$} & \multicolumn{2}{|c|}{$\begin{array}{c}\text { Center line } \\
\text { reactor }\end{array}$} \\
\hline
\end{tabular}

${ }^{a}$ Pin locations are in accordance with drawings at bottom of table. $A=$ top pin;

$B=$ middle pins; $C=$ bottom pin. Center of the middle pin located at midplane of reactor core. 


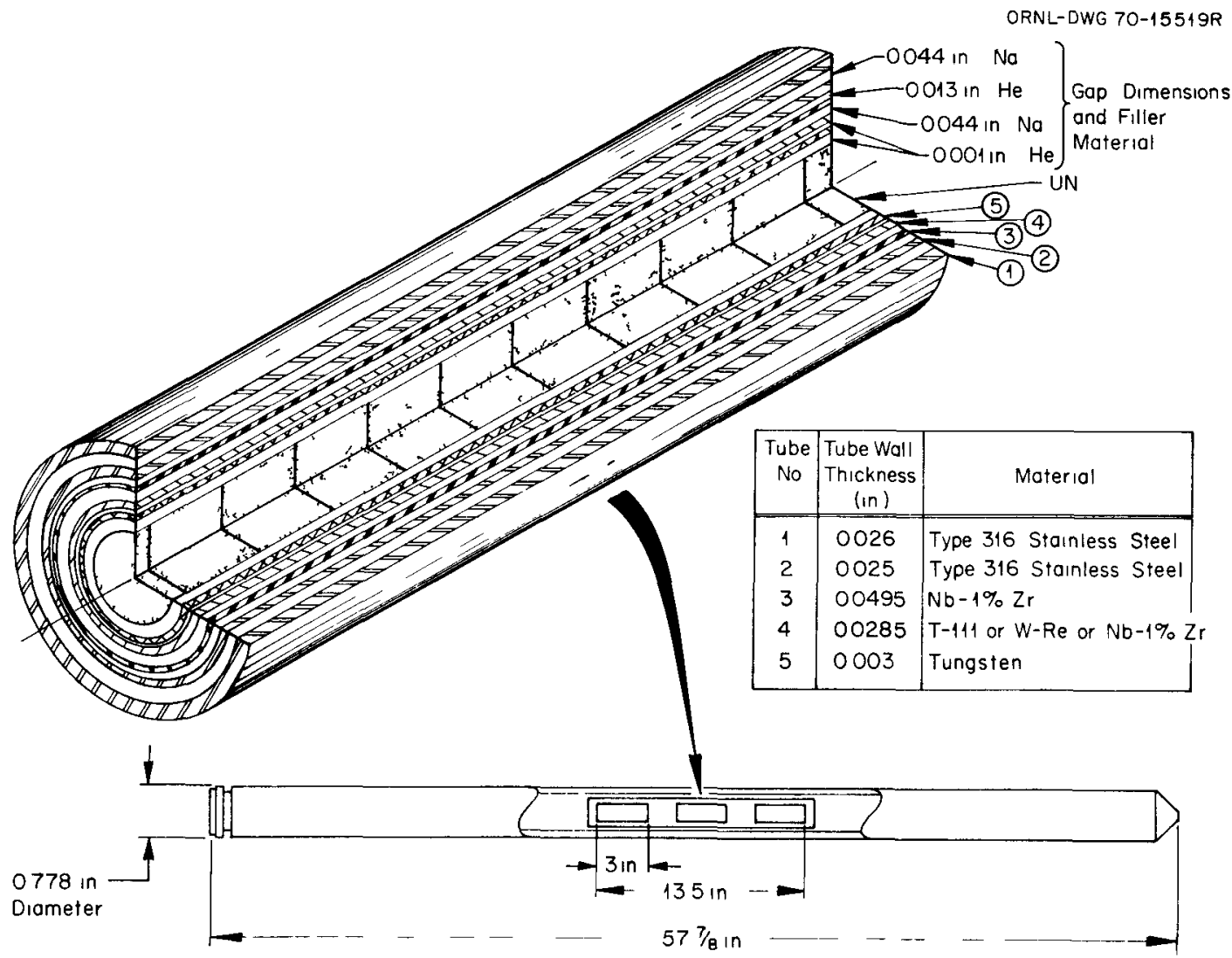
EBR-II.

Fig. 11.8. Capsule for Irradiation of UN and Refractory Metal in

\section{Notes}

1. The current program includes work sponsored by the AEC and work sponsored by NASA under Interagency Agreement 40-184-69, NASA Order C-54536-B. Specifically, capsules UN-1, UN-2, UN-3, and UN-5 are funded by the AEC, and capsules UN-4 and UN- 6 are funded by NASA.

2. On loan from Reactor Chemistry Division.

3. D. R. Cuneo, Fuels and Materials Development Program Quart. Progr. Rept. Dec. 31, 1969, ORNL-4520, pp. 195-201.

4. D. R. Cuneo and E. L. Long, Jr., Fuels and Materials Development Program Quart. Progr. Rept. March 31, 1970, ORNL-4560, pp. 165-172.

5. D. R. Cuneo and E. I. Long, Jr., Fuels and Materials Development Program Quart. Progr. Rept. June 30, 1970, ORNL-4600, pp. 177-180.

6. E. I. Long, Jr. and D. R. Cuneo, Fuels and Materials Development Program Quart. Progr. Rept. Sept. 30, 1970, ORNL-4630, pp. 180-185. 
7. S. C. Weaver, K. R. Thoms, and V. A. DeCarlo, Trans. Am. Nucl. Soc. $\underline{\underline{12}}(2), 547$ (1969).

8. R. F. Hilbert et al., Trans. Am. Nucl. Soc. 13, 102 (1970).

9. On Ioan from Australian Atomic Energy Commission.

10. K. Farrell, J. T. Houston, and A. C. Schaffhauser, "The Growth of Grain Boundary Gas Bubbles in Chemically Vapor Deposited Tungsten," pp. 363-390 in Proceedings of the Conference on Chemical Vapor Deposition of Refractory Metals, Alloys, and Compounds, Gatlinburg Tennessee, September 12-14, 1967, ed. by A. C. Schaffhauser, American Nuclear Society, Hinsdale, Illinois.

11. J. 0. Stiegler et al., ASM (Am. Soc. Metals) Trans. Quart. 60 (3), 494-503 (September 1967).

12. R. I. Stephenson and H. E. McCoy, J. Less-Common Metals 15, 415 (1968).

13. On loan from General Engineering Division. 